\title{
EFFECTS OF HORMONES ON THE MATURATION OF RABBIT OOCYTES RECOVERED FROM FOLLICLES OF VARIOUS SIZES
}

\author{
IN-HA BAE AND R. H. FOOTE \\ Department of Animal Science, Cornell University, \\ Ithaca, New York 14853, U.S.A. \\ (Received 21st Fune 1974)
}

\begin{abstract}
Summary. Progesterone stimulated oocytes to develop more rapidly in culture. The time-dependent effect was more pronounced on large preovulatory Graafian follicles than on small- and medium-sized follicles. Treatment with $\mathrm{LH}$ had no effect.
\end{abstract}

Hormones have been reported to affect the development of follicular oocytes in vitro. Robertson \& Baker (1969) showed that progesterone, but not oestrogen, increased polar body formation and germinal vesicle breakdown in rabbit and bovine oocytes in vitro. Foote \& Thibault (1969) also suggested that a deficiency of steroid hormone was responsible for the failure of cow and pig oocytes to mature within follicles in vitro. Addition of $\mathrm{LH}$ to the culture medium resulted in 84 to $95 \%$ of oocytes within intact follicles showing germinal vesicle breakdown, even though these oocytes were blocked at several intermediate stages of meiosis, and the mediation of adenyl cyclase and possibly of prostaglandins was suggested (Tsafriri, Lindner, Zor \& Lamprecht, 1972). Baker \& Neal (1972), however, showed that if the follicles were smaller than those which normally ovulated, meiotic maturation was not completed. The present investigation was a study of the effect of pyruvate, glutamine, progesterone and LH on the maturation in vitro of rabbit oocytes from follicles of various sizes.

Oocytes were recovered from ovaries freshly removed from 5-month-old virgin Dutch rabbits. The ovaries were cut, placed under a dissecting microscope and the Graafian follicles were punctured with sharp needles. Oocytes were pooled, washed and incubated at $37^{\circ} \mathrm{C}$ in an humidified environment with $5 \% \mathrm{CO}_{2}$ and air as previously described (Bae \& Foote, 1974a).

The compounds under study were added to a basic salt medium containing $0.4 \%$ bovine serum albumin (BSA) and antibiotics (Bae \& Foote, 1974a). Progesterone was made up to give a final concentration of $32 \mu \mathrm{g} / \mathrm{ml}$ of the culture medium. Pituitary LH (P.L.H.: Armour-Baldwin Lab.) was added to culture medium with pyruvate, or glutamine to give a final concentration of $5 \mu \mathrm{g} / \mathrm{ml}$ (equivalent to $5 \mu \mathrm{g}$ of the Armour standard).

The results of adding pyruvate, glutamine, progesterone and LH are given in Table 1 (Exp. I). The limited development in the salt medium with BSA agrees with previous results (Bae \& Foote, 1974a). Pyruvate markedly stimu- 


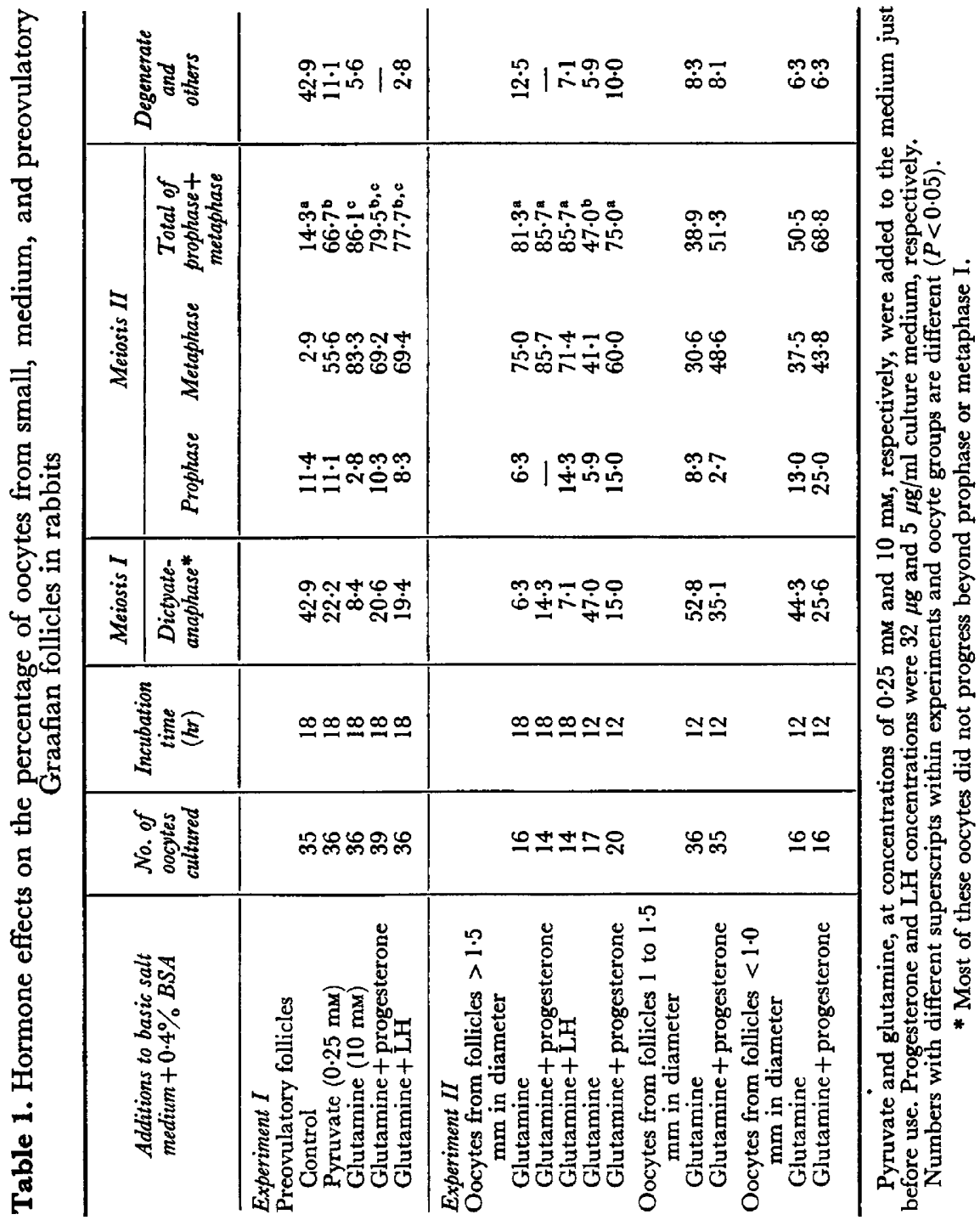


lated development, but glutamine was more effective $(P<0.05)$, as was found by Bae \& Foote (1974b) in work with rabbit oocytes and by Brinster (1970) and Kane (1972) in studies with rabbit embryos. Thus, amino acids or other fixed nitrogen sources may substitute for carbohydrates as an energy source. Neither progesterone nor LH, at the levels used, affected development significantly $(P>0.05)$. In a separate experiment, twenty-three of forty-three $(56 \%)$ embryos developed to meiosis II in a pyruvate-containing medium to which LH $(5 \mu \mathrm{g} / \mathrm{ml})$ had been added. This was not different from a corresponding value of $66 \%$ for forty-seven embryos cultured in the pyruvate medium without LH. Only $20 \%$ of forty-five embryos developed in the basic salt medium containing BSA.

Oocytes from follicles of different sizes were cultured for 12 or $18 \mathrm{hr}$ in media containing progesterone or LH (Exp. II, Table 1). Progesterone had a striking effect on hastening the development of large follicular oocytes, but the stimulatory effect on oocytes from small follicles failed to reach statistical significance $(P>0.05)$. Experiments without oil or BSA would be desirable because Quinn (1973) has shown that progesterone may migrate into the oil layer and progesterone may be absorbed by BSA (R. H. Foote and M. G. Allen, unpublished observation).

Our results are similar to those of Robertson \& Baker (1969). Baker \& Neal (1972) showed that meiosis resumption beyond the dictyate stage could only be induced by HCG treatment in those oocytes which were of an appropriate size. This may indicate that not all small and medium-sized Graafian follicles in the present experiment were ready to resume meiosis. Our results are in contrast to those of Tsafriri et al. (1972) who worked with rats and used a different culture system. Tsafriri, Lieberman, Barnea, Bauminger \& Lindner (1973) found that ovum maturation continued when progesterone synthesis stimulated by LH was blocked by actinomycin D, but it would seem from our results that progesterone and LH may still be involved in oocyte maturation. Oocyte development and ovulation may be regulated by different factors: Jagiello (1968) showed that in the mouse oocyte maturation could take place in the follicle but ovulation might not occur. Conversely, ovulation can be induced before normal oocyte maturation can take place (Espey \& Lipner, 1965). Lipner \& Greep (1971) have suggested that ovulation is related to maturation by the induction of steroidogenesis, and Espey (1971) believed that the primary rôle of LH in ovulation might be to transform the mature follicle into a highly active steroidsecreting structure.

Further experiments are required to isolate the possible effects of the hormones directly on the oocyte or indirectly through action on other follicular components.

We wish to thank Mr Michael Simkin for excellent technical assistance. This study was partly supported by a fellowship from the Population Council in New York to one of us (I-H.B.). 


\section{REFERENCES}

BAE, I.-H. \& Foote, R. H. (1974a) Carbohydrate and amino acid requirements for maturation of rabbit follicular oocytes in vitro. Expl Cell Res. (in press).

BAE, I.-H. \& Foote, R. H. (1974b) Utilization of glutamine for energy and protein synthesis by cultured rabbit follicular oocytes. Expl Cell Res. (in press).

BAKER, T. G. \& NEAL, P. (1972) Gonadotrophin-induced maturation of mouse graafian follicles in organ culture. In Oogenesis, pp. 377-396. Eds. J. D. Biggers and A. W. Schuetz. University Park Press, Baltimore.

Brinster, R. L. (1970) Culture of two-cell rabbit embryos to morulae. F. Reprod. Fert. 21, 17-22.

ESPEY, L. L. (1971) Decomposition of connective tissue in rabbit ovarian follicles by multivesicular structures of thecal fibroblasts. Endocrinology, 88, 437-444.

Espey, L. L. \& Lipner, H. (1965) Enzyme-induced rupture of rabbit graafian follicle. Am. F. Physiol. 208, 208-213.

Foote, W. D. \& Thibault, C. (1969) Recherches expérimentales sur la maturation in vitro des ovocytes de truie et de veau. Annls Biol. anim. Biochim. Biophys. 9, 329-349.

JAGIELLo, G. M. (1968) Meiosis and inhibition of ovulation in mouse eggs treated with actinomycin D. 7. Cell Biol. 42, 571-574.

KANE, M. T. (1972) Energy substrates and culture of single cell rabbit ova to blastocysts. Nature, Lond. 238, 468-469.

LIPNER, H. \& GREEP, R. O. (1971) Inhibition of steroidogenesis at various sites in the biosynthetic pathway in relation to induced ovulation. Endocrinology, 88, 602-607.

Quins, P. (1973) Effect of steroids on cleaving embryos in vitro. Fackson Laboratory Report, 1972-1973, p. 51 .

Robertson, J. E. \& BAKER, R. D. (1969) Role of female sex steroids as possible regulators of oocyte maturation. Soc. Study Reprod., 2nd Annual Meeting, Davis, California, Abstr. No. 57, p. 29.

Tsafriri, A., Lreberman, M. E., Barnea, A., Bauminger, S. \& Lindner, H. R. (1973) Induction by luteinizing hormone of ovum maturation and of steroidogenesis in isolated graafian follicles of the rat: role of RNA and protein synthesis. Endocrinology, 93, 1378-1386.

TSAPriri, A., Lindner, H. R., ZoR, U. \& LAMprecht, S. A. (1972) In-vitro induction of meiotic division in follicle-enclosed rat oocytes by LH, cyclic AMP and prostaglandin $\mathrm{E}_{2} . \mathcal{F}$. Reprod. Fert. 31, 39-50. 